\title{
Near-Adult Heights and Adult Height Predictions Using Automated and Conventional Greulich-Pyle Bone Age Determinations in Children with Chronic Endocrine Diseases
}

\author{
Daniela Choukair ${ }^{1}$ (1) Annette Hückmann ${ }^{1}$. Janna Mittnacht ${ }^{1} \cdot$ Thomas Breil $^{1}$. Jens Peter Schenk ${ }^{2}$. \\ Abdulsattar Alrajab ${ }^{2} \cdot$ Lorenz Uhlmann $^{3} \cdot$ Markus Bettendorf $^{1}$
}

Received: 8 June 2021 / Accepted: 24 September 2021/Published online: 1 February 2022

(C) The Author(s) 2022

\begin{abstract}
Objectives To validate adult height predictions (BX) using automated and Greulich-Pyle bone age determinations in children with chronic endocrine diseases.

Methods Heights and near-adult heights were measured in 82 patients (48 females) with chronic endocrinopathies at the age of $10.45 \pm 2.12 \mathrm{y}$ and at time of transition to adult care $(17.98 \pm 3.02 \mathrm{y})$. Further, bone age (BA) was assessed using the conventional Greulich-Pyle (GP) method by three experts, and by BoneXpert ${ }^{\mathrm{TM}}$. PAH were calculated using conventional BP tables and BoneXpert ${ }^{\mathrm{TM}}$.

Results The conventional and the automated BA determinations revealed a mean difference of $0.25 \pm 0.72$ y $(p=0.0027)$. The automated PAH by BoneXpert ${ }^{\mathrm{TM}}$ were $156.26 \pm 0.86 \mathrm{~cm}$ (SDS $-2.01 \pm 1.07$ ) in females and $171.75 \pm 1.6 \mathrm{~cm}$ (SDS - 1.29 \pm 1.06$)$ in males, compared to $153.95 \pm 1.12 \mathrm{~cm}(\mathrm{SDS}-2.56 \pm 1.5)$ in females and $169.31 \pm 1.6 \mathrm{~cm}$ (SDS $-1.66 \pm 1.56$ ) in males by conventional BP, respectively and in comparison to near-adult heights $156.38 \pm 5.84 \mathrm{~cm}$ (SDS $-1.91 \pm 1.15$ ) in females and $168.94 \pm 8.18 \mathrm{~cm}$ (SDS $-1.72 \pm 1.22$ ) in males, respectively.

Conclusion BA ratings and adult height predictions by BoneXpert ${ }^{\mathrm{TM}}$ in children with chronic endocrinopathies abolish rater-dependent variability and enhance reproducibility of estimates thereby refining care in growth disorders. Conventional methods may outperform automated analyses in specific cases.
\end{abstract}

Keywords Automated bone age · Greulich-Pyle · Adult height predictions · Children with chronic endocrine diseases

\section{Introduction}

Growth failure is very common in patients with chronic endocrinopathies, and the determination of skeletal maturity (bone age, BA) plays a pivotal role in endocrine diagnostic and is important to evaluate the individual growth potential $[1,2]$. The most widely used methods for BA assessment are the

Daniela Choukair

daniela.choukair@med.uni-heidelberg.de

1 Division of Pediatric Endocrinology and Diabetology, University Children's Hospital Heidelberg, Heidelberg 69120, Germany

2 Pediatric Radiology, University of Heidelberg, Heidelberg, Germany

3 Institute of Medical Biometry and Informatics, University of Heidelberg, Heidelberg, Germany
Tanner-Whitehouse (TW2, TW3) methods [3, 4] and Greulich and Pyle (GP) method. For the latter, a trained rater with a background of pediatric endocrinology or pediatric radiology performs comparisons with the plates of the GP atlas from 1959 [4]. This manual procedure is time-consuming, requires experience, and is susceptible to considerable inter- and intrarater variability [2].

Recently, an automated image analysis method, BoneXpert $^{\mathrm{TM}}$ has been introduced [5] and has been validated in patients with different endocrinopathies and with chronic renal failure [6-8]. BoneXpert ${ }^{\mathrm{TM}}$ uses an adopted adult height prediction method (BX), which is an improvement and extension of the Bayley-Pinneau method (BP) [9]. So far, it is validated for healthy children [10]. The objectives of this study were the validation of adult height predictions (BX) using automated Greulich-Pyle bone age determinations in children with chronic endocrine diseases. Therefore, these results were compared to adult height prediction 
calculations (BP), based on conventional assessments of GP performed by three independent experienced clinicians and to near-adult heights at the time of transition from pediatric to adult care.

\section{Material and Methods}

At the University's Hospital, 88 consecutive adolescents with chronic endocrine diseases were evaluated after achieving the primary pediatric treatment goals (girls: bone age $\geq 14$ $\mathrm{y}$ and menarche; boys: bone age $\geq 16 \mathrm{y}$ and voice brake) when $>98 \%$ of final adult height was reached and negligible growth potential was left [11]. To take part into this retrospective study written informed consent was obtained from each participant and their parents. The ethics committees of the University of Heidelberg approved the study which was performed according to the Declaration of Helsinki and conformed to legal and ethical norms (S-019/2011).

Six of the consecutive 88 patients were excluded as one radiograph of the left hand was unavailable and Digital Imaging and Communication in Medicine (DICOM) datasets from five patients were ineligible. Therefore, 82 radiographs of 48 females and 34 males were analyzed and corresponding heights were measured in an upright position, using a wall-mounted Harpenden stadiometer (Mentone Educational, Moorabbin, Victoria, Australia) at the chronological age of $10.45 \pm 2.12 \mathrm{y}$ and at time of transition $(17.98 \pm 3.02$ y). Reference percentiles of Brandt and Reinken were used for calculation of standard deviation scores (SDS) [12].

Medications and information on potential osseous disorders were available. Patients with the following diagnoses were included: congenital adrenal hyperplasia (CAH), isolated growth hormone deficiency (iGHD), panhypopituitarism (MPHD), small for gestational age (SGA), and Ullrich-Turner syndrome (UTS). For the details of patients' characteristics, see Table 1. All patients were treated according to international consensus guidelines [13-16].

Two pediatric radiologists and one pediatric endocrinologist determined BA according to the atlas method of GP [4]. Since this method gives BA values at nonlinear intervals, $\mathrm{BA}$ is expressed as average of the younger and older BA respectively, when estimated BA was between the defined bone ages. For further statistical analysis, the mean of these three independent determinations of BA was used; named conventional BA and inter-rater variability was calculated. In addition, the automated assessment of BA was performed by BoneXpert ${ }^{\mathrm{TM}}$ version 2.1 (named automated BA, BoneXpert $^{\mathrm{TM}}$, Visiana, Holte, Denmark, www.boneXpert.com). A more detailed description of this method is published elsewhere [17]. In brief, the automated BA consists of three layers of computation [17]. Layer A reconstructs and validates the borders of 15 bones: radius, ulna, all metacarpals, and the phalanges of finger I, III, V. The bone will be rejected if it is not placed correctly or it is severely dysmorphic. Layer B determines a so called intrinsic BA for each bone of the RUS bones (except metacarpal II and IV). Bones with BA deviated more than $2.4 \mathrm{y}$ of the average BA were rejected. Average BA will not be calculated if less than 8 bones out of 13 were accepted. Layer $\mathrm{C}$ transforms the intrinsic BA into the scale of GP or TW. At the time of this study the BoneXpert ${ }^{\mathrm{TM}}$ covered the BA ranges $2.5-17$ y for boys and $2-15$ y for girls.

Height predictions were calculated using the conventional BA according to the methods of Bayley-Pinneau for girls and boys (conventional BP) [18] calculated by the anthropometric software GrowthXP from PC PAL, Stockholm, Sweden. Adult

Table 1 Patient characteristics at the time of transition from pediatric to adult care and heights (SDS) at mean chronological age of $10.5 \pm 2.1 \mathrm{y}$

\begin{tabular}{|c|c|c|c|c|c|c|c|}
\hline Diagnosis & Gender & Total & $\mathrm{CAH}$ & iGHD & MPHD & SGA & UTS \\
\hline Gender $(\mathrm{f} / \mathrm{m}) n$ & & $82(48 / 34)$ & $15(7 / 8)$ & $22(9 / 13)$ & $10(5 / 5)$ & $17(9 / 8)$ & $18(18 /-)$ \\
\hline Chronological age (y) & & $17.98 \pm 3.02$ & $19.14 \pm 2.63^{\#+}$ & $17.45 \pm 2.23^{+\#}$ & $21.34 \pm 4.67 *+\&$ & $15.75 \pm 1.31^{\# * \& \#}$ & $18.18 \pm 2.00^{\#+}$ \\
\hline \multirow[t]{2}{*}{ Near-adult height $(\mathrm{cm})$} & female & $156.38 \pm 5.84$ & $159.89 \pm 3.82^{+\&}$ & $159.56 \pm 5.77^{+}$ & $160.03 \pm 7.23^{+\&}$ & $152.87 \pm 4.44^{* \$}$ & $154.13 \pm 4.93 * \$ \#$ \\
\hline & male & $168.94 \pm 8.18$ & $173.33 \pm 7.37^{+\$}$ & $168.73 \pm 6.42^{+*}$ & $170.36 \pm 9.29^{+\&}$ & $164.0 \pm 4.75^{+\$ \#}$ & - \\
\hline Near-adult heights SDS & & $-1.72 \pm 1.2$ & $-1.13 \pm 0.96^{+\&}$ & $-1.42 \pm 1.03^{\&}$ & $-1.25 \pm 1.78^{\&}$ & $-2.12 \pm 0.89 *$ & $-2.51 \pm 0.98 * \S^{\sharp}$ \\
\hline \multirow[t]{2}{*}{ Target height $(\mathrm{cm})$} & female & $161.87 \pm 5.82$ & $161.86 \pm 5.46$ & $162.69 \pm 4.06$ & $163.33 \pm 6.54^{+}$ & $157.0 \pm 7.13^{\# \&}$ & $163.46 \pm 4.85^{+}$ \\
\hline & male & $175.34 \pm 6.42$ & $176.88 \pm 5.81$ & $174.34 \pm 5.54$ & $176.6 \pm 10.34$ & $174.63 \pm 6.31$ & - \\
\hline Target height SDS & & $-0.88 \pm 1.09$ & $-0.72 \pm 1.00$ & $-0.95 \pm 0.90$ & $-0.42 \pm 1.24$ & $-1.41 \pm 1.3$ & $-0.70 \pm 0.95$ \\
\hline \multicolumn{8}{|l|}{$\begin{array}{l}\text { Differences } \\
\text { Near-adult heights-SDS }\end{array}$} \\
\hline Target heights SDS & & $-0.84 \pm 1.09$ & $-0.41 \pm 0.98^{\&}$ & $-0.47 \pm 0.79^{\&}$ & $-0.83 \pm 1.12^{\&}$ & $-0.71 \pm 1.16^{\&}$ & $-1.81 \pm 0.86^{* \S \#+}$ \\
\hline
\end{tabular}

$C A H$ Congenital adrenal hyperplasia; $f$ Female; $i G H D$ Isolated growth hormone deficiency; $m$ Male; $M P H D$ Panhypopituitarism; SDS Standard deviation score; SGA Small for gestational age; UTS Ullrich-Turner syndrome

Data are given as mean \pm standard deviation (SD). Statistics by ANOVA: ${ }^{*} p<0.05$ vs. CAH; ${ }^{\S} p<0.05$ vs. GHD; ${ }^{*} p<0.05$ vs. MPHD; ${ }^{+} p<0.05$ vs. SGA; ${ }^{\&} p<0.05$ vs. UTS 
Table 2 Comparison of conventional bone age determination according to Greulich and Pyle (conventional BA) and automated bone age determination (automated BA)

\begin{tabular}{lcccccc}
\hline Diagnosis & Total & CAH & iGHD & MPHD & SGA & UTS \\
\hline Chron. age (CA; y) & $10.45 \pm 2.12$ & $8.75 \pm 1.60^{\S \# \&}$ & $11.16 \pm 1.85^{*+}$ & $12.12 \pm 2.02^{*+}$ & $9.66 \pm 1.53^{\S \#}$ & $10.82 \pm 2.22^{*}$ \\
Automated BA (y) & $9.59 \pm 1.86$ & $10.78 \pm 1.85^{+}$ & $9.63 \pm 2.08^{+}$ & $9.60 \pm 1.6$ & $8.43 \pm 1.45^{* \& \&}$ & $9.67 \pm 1.51^{+}$ \\
Differences & $-0.86 \pm 2.26$ & $2.04 \pm 2.67^{\S \#+\&}$ & $-1.53 \pm 1.67^{*}$ & $-2.52 \pm 2.01^{*}$ & $-1.23 \pm 1.05^{*}$ & $-1.15 \pm 1.5^{*}$ \\
Automated BA - CA (y) & & & & & & \\
Conventional BA (y) & $9.84 \pm 1.78$ & $11.06 \pm 1.79^{\#+\&}$ & $9.94 \pm 1.99$ & $9.80 \pm 1.57^{*}$ & $8.98 \pm 1.43^{*}$ & $9.66 \pm 1.52^{*}$ \\
Differences & $-0.61 \pm 2.20$ & $2.32 \pm 2.57^{\S \#+\&}$ & $-1.22 \pm 1.55^{*}$ & $-2.32 \pm 1.8^{*+}$ & $-0.68 \pm 0.97^{* \#}$ & $-1.16 \pm 1.46^{*}$ \\
Conventional BA - CA (y) & & & & & & \\
Differences & $-0.25 \pm 0.72$ & $-0.28 \pm 0.69$ & $-0.31 \pm 0.57$ & $-0.2 \pm 0.97$ & $-0.54 \pm 0.77^{\&}$ & $0.01 \pm 0.68$ \\
Automated BA - Conventional BA (y) & & & & & & \\
\hline
\end{tabular}

$B A$ Bone age; $C A$ Chronological age; $C A H$ Congenital adrenal hyperplasia; $f$ Female; $i G H D$ Isolated growth hormone deficiency; $m$ Male; MPHD Panhypopituitarism; SGA Small for gestational age; UTS Ullrich-Turner syndrome

Data are given as mean \pm standard deviation (SD). Statistics by ANOVA: ${ }^{*} p<0.05$ vs. CAH; ${ }^{\S} p<0.05$ vs. GHD; ${ }^{\#} p<0.05$ vs. MPHD; ${ }^{+} p<0.05$ vs. SGA; ${ }^{\&} p<0.05$ vs. UTS

height predictions for girls and boys using the automated BA were calculated with BoneXpert ${ }^{\mathrm{TM}}$ (automated BX) according to Thodberg et al. [9] on www.bonexpert.com. Briefly, the growth potential (gp) was defined as: $g p=(H-h) / H$ when $\mathrm{H}$ equals adult height and $\mathrm{h}$ represents actual height. The growth potential prediction is denoted $g p_{\text {pred }}(\mathrm{BA}, \mathrm{CA}-\mathrm{BA})$, from this the so-called raw prediction of the adult height is derived: $H_{\text {raw }}=h /\left(1-g p_{\text {pred }}\right)$. The new method constructs $g p_{\text {pred }}(B A, C A$ $-B A$ ) as a nonlinear function of two variables. This is implemented as one neural network (a standard nonlinear regression method) for each gender as described in detail elsewhere [9]. In addition, target heights ( $\mathrm{cm}$; SDS) were calculated with the formula of Tanner (midparental height $(+6.5$ in boys or -6.5 in girls), respectively) [19].

Data are given as mean \pm standard deviation (SD), if not indicated otherwise. The differences between the conventional and automated BA were described using a Bland-Altman plot. The overall bias and limits of agreement are provided. Interrater variability expressed as Fleiss' $\kappa$ was also calculated. All data were assessed for normal distribution by the Kolmogorov-Smirnov test. Correlation coefficients were calculated according to Pearson. A $p$ value $<0.05$ was considered as statistically significant. Since this was an exploratory analysis, no adjustment for multiple testing was done. Stat View version 5.0 1998 and the software $\mathrm{R}$ in combination with the package psychometric were used for statistical analysis [20,21].

\section{Results}

None of the 82 analyzed images were rejected by BoneXpert $^{\mathrm{TM}}$. The inter-rater variability of the conventional BA determination according to Greulich and Pyle performed by three experienced raters was 0.88 .
There was a good correlation between the conventional and the automated bone age ratings $(r=0.843 ; p<0.001)$. The automated and the conventional BA determinations differed by $-0.25 \pm 0.72$ y $(p=0.0027)$ (Table 2$)$ ranging from -1.67 to $1.19 \mathrm{y}$. The conventional method tended to rate bone ages slightly more mature. The exact distribution is shown in Fig. 1 using a Bland-Altman plot. Further, the mean differences between the automated and conventional method for female and male patients were significantly different (females, $-0.16 \pm 0.68 \mathrm{y}$; males, $-0.37 \pm 0.77 \mathrm{y}$; $p=0.001)$.

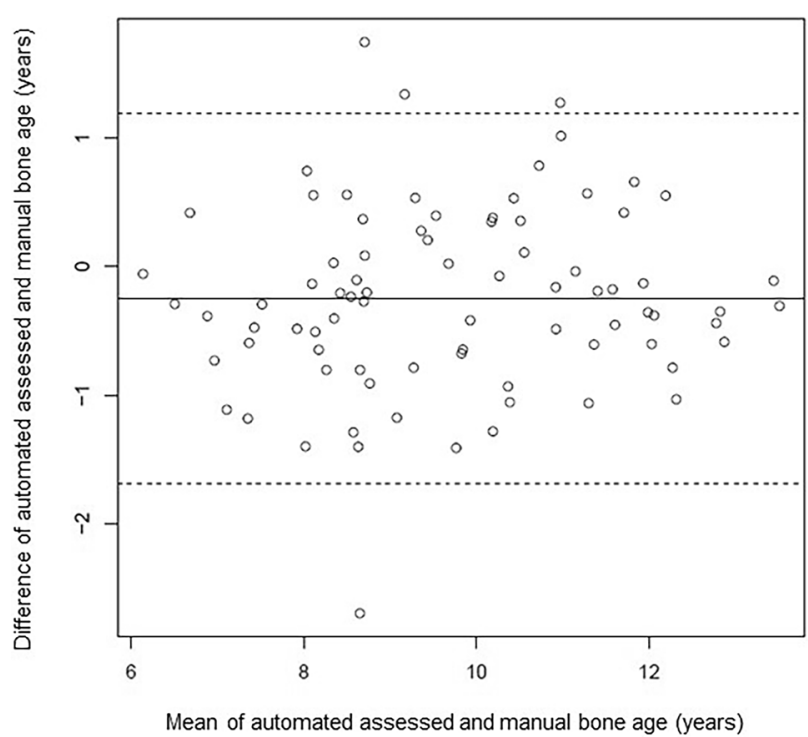

Fig. 1 Bland-Altman plot demonstrates the relationship between automated and conventional bone age ratings (mean of three independent ratings). The differences between the two methods are depicted against the mean of these two methods. The dashed lines indicate 2 SD 


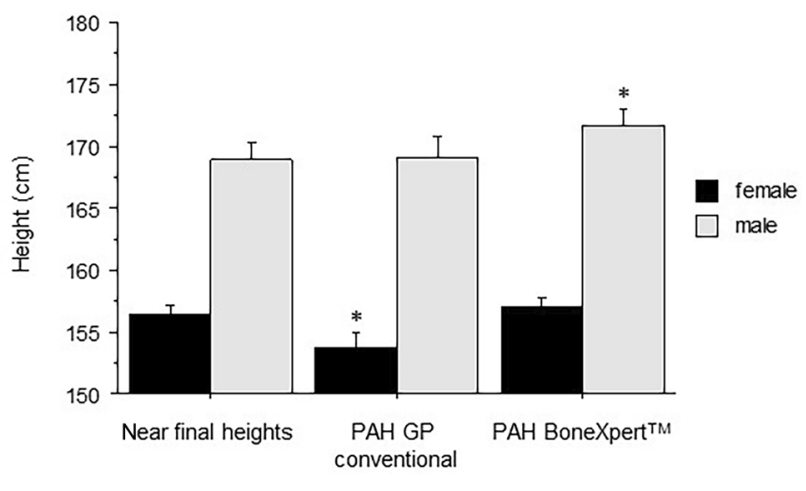

Fig. 2 Near-adult heights $(\mathrm{cm})$ and adult height predictions $(\mathrm{cm})$ using the tables of Bayley- Pinneau and conventionally determined bone age according to Greulich and Pyle (conventional BP), and by BoneXpert ${ }^{\mathrm{TM}}$ (automated $\mathrm{BX}$ ), respectively are depicted. Mean $\pm \mathrm{SD}$, *indicating $p<$ 0.05. (SDS-Near-final heights: Females: $-1.91 \pm 1.15$; Males: $-1.72 \pm 1.22$; PAH GP conventional Females: $-2.56 \pm 1.5$; Males: $-1.66 \pm 1.56$; PAH BoneXpert TM Females: $-2.01 \pm 1.07$; Males: $-1.29 \pm 1.06$ )

Overall the automated BA was retarded by $0.86 \pm 2.26$ $\mathrm{y}$ (Table 2). The respective bone ages were accelerated by $2.04 \mathrm{y}$ in $\mathrm{CAH}$, but retarded in MPHD by $-2.52 \mathrm{y}$, and moderately retarded in SGA, UTS, and iGHD (Table 2). Conventional and automated bone age determinations were similar in all patient groups $(p=n s)$, except in patients with SGA $(p<0.05)$ (Table 2).

The mean near-adult heights in females and in males [females $156.38 \pm 5.84 \mathrm{~cm}(\mathrm{SDS}-1.91 \pm 1.15)$, males $168.94 \pm 8.18 \mathrm{~cm}$ (SDS $-1.72 \pm 1.22)$ ] were significantly lower than target heights in females $[161.87 \pm 5.82 \mathrm{~cm}(\mathrm{SDS}-1.00 \pm 1.14)]$ and in males $[175.34 \pm 6.42 \mathrm{~cm}(\mathrm{SDS}-0.71 \pm 1.00)]$, respectively $(p<0.001)$ (Table 1$)$.

The predicted adult heights using the method of BoneXpert $^{\mathrm{TM}}$ (automated BX) were $156.26 \pm 0.86 \mathrm{~cm}$ (SDS $-2.01 \pm 1.07)$ in girls matching near-adult heights $(\Delta 0.58 \pm 0.84 \mathrm{~cm} ; p=\mathrm{ns})$ (Fig. 2). In contrast, the predicted adult heights using conventional BP were $153.95 \pm 1.12 \mathrm{~cm}(\mathrm{SDS}-2.56 \pm 1.5)$, in girls underestimating near-adult heights by $2.43 \pm 0.84 \mathrm{~cm}(p<0.01)$ (Fig. 2). The automated BX were $171.75 \pm 1.6 \mathrm{~cm}$ (SDS $-1.29 \pm 1.06)$, in boys, overestimating near-adult heights by $2.81 \pm 2 \mathrm{~cm}(p<0.05)$ (Fig. 2). Conventional $\mathrm{BP}$ in boys corresponded to near-adult heights in boys $[169.31 \pm 1.6 \mathrm{~cm}(\mathrm{SDS}-1.66 \pm 1.56)] ; \Delta 0.37 \pm 1.4 \mathrm{~cm}$; $p=$ ns) (Fig. 2).

Conventional BP and automated BX were analyzed separately in CAH and MPHD because of distinct differences in bone ages and chronological ages (CAH: $2.04 \pm 2.67$ y; MPHD: $-2.52 \pm 2.01 \mathrm{y}$, respectively). Predicted adult heights using both methods were similar as near-adult heights in females regardless of bone age acceleration and retardation (Table 3). Automated BX overestimated significantly predicted adult heights in males with MPHD when bone ages were retarded $(9.3 \pm 3.02 \mathrm{~cm} ; p<0.05)$ (Table 3).

\section{Discussion}

As far as the authors know, this study represents the first comparison of observed near-final heights and the recent adult height calculation method based on automated bone
Table 3 Predicted adult heights using the method of BayleyPinneau (conventional BP) and BoneXpert $^{\mathrm{TM}}$ (automated BX) in patients with accelerated bone age (BA) [congenital adrenal hyperplasia $(\mathrm{CAH})]$ and delayed BA [panhypopituitarism (MPHD)]

\begin{tabular}{|c|c|c|c|c|c|}
\hline & & $\begin{array}{l}\text { CAH } \\
(\mathrm{cm})\end{array}$ & $\begin{array}{l}\text { CAH } \\
\text { (SDS) }\end{array}$ & $\begin{array}{l}\text { MPHD } \\
(\mathrm{cm})\end{array}$ & $\begin{array}{l}\text { MPHD } \\
\text { (SDS) }\end{array}$ \\
\hline \multirow[t]{3}{*}{ Female } & Near-adult heights & $160.0 \pm 3.8$ & $\begin{array}{l}-1.37 \pm \\
0.75\end{array}$ & $161.5 \pm 7.1$ & $\begin{array}{l}-1.08 \pm \\
1.42\end{array}$ \\
\hline & Conventional BP & $160.0 \pm 8.3$ & $\begin{array}{l}-1.37 \pm \\
1.64\end{array}$ & $162.5 \pm 6.6$ & $\begin{array}{l}-0.88 \pm \\
1.33\end{array}$ \\
\hline & Automated BX & $162.2 \pm 6.0$ & $\begin{array}{l}-0.94 \pm \\
1.17\end{array}$ & $162.6 \pm 2.8$ & $\begin{array}{l}-0.86 \pm \\
1.05\end{array}$ \\
\hline \multirow[t]{3}{*}{ Male } & Near-adult heights & $173.3 \pm 7.4$ & $\begin{array}{l}-1.03 \pm \\
1.13\end{array}$ & $170.4 \pm 6.4$ & $\begin{array}{l}-1.48 \pm \\
2.26\end{array}$ \\
\hline & Conventional BP & $170.0 \pm 9.6$ & $\begin{array}{l}-1.55 \pm \\
1.61\end{array}$ & $173.6 \pm 7.9$ & $\begin{array}{l}-0.98 \pm \\
2.76\end{array}$ \\
\hline & Automated BX & $177.5 \pm 6.5$ & $\begin{array}{l}-0.38 \pm \\
1.02\end{array}$ & $179.7 \pm 4.9^{*}$ & $\begin{array}{l}-0.33 \pm \\
0.77\end{array}$ \\
\hline
\end{tabular}

CAH Congenital adrenal hyperplasia; $M P H D$ Panhypopituitarism

The difference of conventional BA and chronological age (CA) in patients with CAH was $2.32 \pm 2.57 \mathrm{y}$ and was $2.04 \pm 2.67 \mathrm{y}$ when BA was estimated by BoneXpert ${ }^{\mathrm{TM}}$ (automated BA). The difference of conventional BA and CA in patients with MPHD was $-2.32 \pm 1.8$ y and was $-2.52 \pm 2.01$ y when automated BA was utilized. Data are given as mean \pm standard deviation (SD). Statistics by $t$-test: $* p<0.05$ vs. near adult height 
age determination (BoneXpert ${ }^{\mathrm{TM}}$ ) with the conventional PAH method by Bayley - Pinneau based on bone age determination according to Greulich and Pyle in children with various chronic endocrinopathies. In general, there was a good agreement of automated BX in girls, regardless of bone age deviations from chronological age. The recent method of automate $\mathrm{BX}$ implements a nonlinear growth potential function [9]. This is more graduated and therefore more precise than the conventional BP using the tables of Bayley - Pinneau which rates only for three ranges namely advanced $(\mathrm{BA}>\mathrm{CA}>1 \mathrm{y})$, normal $\mathrm{BA}$ $(\mathrm{CA}=\mathrm{BA} \pm 1 \mathrm{y})$ and retarded $(\mathrm{BA}<\mathrm{CA}<-1 \mathrm{y})$. The present results applying automated $\mathrm{BX}$ in girls are in accordance with the results of Unrath et al. [10] and Thodberg et al. [22], who investigated healthy children with short stature. Martin et al. reported a slight underprediction of automated BX in girls with short stature by $0.8 \mathrm{~cm}$ when bone age was younger than $12 \mathrm{y}$ [23]. This observation was explained by an individual, unpredictable growth pattern of six included girls.

Remarkably, automated BX overestimated adult heights in boys, especially, when bone ages were severely retarded. This observation was confirmed by Thodberg et al. [22]. In their study, height predictions in boys using automated BX did not outperform the conventional method in boys indicating an inherent weak spot. It is known, that conventional BP systematically overestimates adult height in boys, especially when bone age is retarded [24] or in constitutional tall stature [25].

These observations cannot be explained by a systematic error in bone age determination of automated BA, because the present study and all other studies reported a good accordance with the conventional BA assessment (Fig. 1 and Table 1) [10,17]. This difference is similar to the deviation between two manual raters [17]. Further, this remarked effect is not caused by incorrect bone age determination due to dysmorphic bones, because none of the images were rejected by BoneXpert ${ }^{\mathrm{TM}}$.

The residual errors of growth prediction in both methods arise from various sources: (a) conventional growth prediction models presumed a linear dependence between adult height and BA, but puberty and its growth spurt are dynamic processes and not concordant with bone age advancement. Each child experiences an individual growth pattern. The tables of Bayley and Pinneau were initially evaluated in healthy children but thereafter adapted as benchmark to children with various growth disorders and treatments. Implementation in clinical routine of growth disorders revealed a valuable tool in treatment control and expectations [26], (b) incorrect measurements of height and (near-) adult heights, (c) unpredictable influences on growth and pubertal development, such as nutrition, genetic, and environmental factors. But a clear advantage using automated $\mathrm{BX}$ is that the bone age determination is not impaired by rater variability and can be therefore easily used for clinical studies. Automated bone age determination by BoneXpert ${ }^{\mathrm{TM}}$ can be used as a reliable tool and efficient method because it is time- and cost-saving. It is reliable also when bone age is accelerated or retarded [6, $7,10]$. Apart from children with chronic kidney disease, in which automated BA tended to underestimate acceleration or retardation of bone age [8], this difference can be probably explained by the renal osteodystrophy in this cohort.

For evaluation of bone morphology, a rating of the radiographs by an expert remains mandatory and cannot be replaced by computerization. A limitation of this study is the small numbers of patients in each group. Therefore, future multicenter studies with a larger sample size are needed to evaluate accuracy of automated BX.

Taking the described limitations into account, the new prediction method is superior to the conventional BP in girls, regardless of bone age deviation from chronological age. Automated BX tends to overestimate PAH in boys, especially, when bone age is retarded.

\section{Conclusion}

Bone age determination is a standard investigation in the workup of growth disturbances in children with various pediatric diseases [27], but also in orthodontics and pediatric orthopedics [28]. Further, it is used for legal issues, especially to determine a person's age, based on skeletal radiographs. However, according to the statement of the European Society of Pediatric Radiology musculoskeletal task force group, exact determination of chronological age of a person cannot be done with sufficient accuracy with existing methods [29]. Based on the bone age determination, several prediction models for adult heights were established. The accuracy of the predicted adult heights is limited due to the growth pattern that can be influenced by medication, nutrition, individual variation in pubertal height gain, and environmental factors [30]. This biological variation is not possible to overcome with mathematical prediction models. Therefore, the accuracy of bone age assessment should be optimized to improve the accuracy of height prediction methods. Using automated bone age determination an inter- and intrarater error is eliminated, and consecutively, reproducibility of adult height prediction improves.

Acknowledgements The authors wish to thank Dr. Hans-Henrik Thodberg, Holte, Denmark for the fruitful support. They also thank the Joachim Siebeneicher Stiftung for financial support. This study was supported by an unrestricted grant of Pfizer, Germany. 
Authors' Contributions DC and MB contributed to the study concept and design, the analysis and interpretation of data and the preparation of the manuscript. AH, JM, TB, JPS, AA, and LU contributed to the analysis and interpretation of data and the revision of the manuscript. All authors participated in acquisition of data and approved the final version of the manuscript. MB will act as the guarantor for this paper.

Funding Open Access funding enabled and organized by Projekt DEAL. Janna Mittnacht has received a Research Grant from Pfizer, Germany. Jens Peter Schenk received a Research Grant from the Joachim Siebeneicher Stiftung, Germany.

\section{Declarations}

Ethics Approval The ethics committees of the University of Heidelberg approved the study which was performed according to the Declaration of Helsinki and conformed to legal and ethical norms (S-019/2011).

Consent to Participate Written consent has been obtained from the parents/caregiver of each patient after full explanation of the purpose and nature of all procedures used.

Code Availability Stat View version 5.0 1998.

\section{Conflict of Interest None.}

Open Access This article is licensed under a Creative Commons Attribution 4.0 International License, which permits use, sharing, adaptation, distribution and reproduction in any medium or format, as long as you give appropriate credit to the original author(s) and the source, provide a link to the Creative Commons licence, and indicate if changes were made. The images or other third party material in this article are included in the article's Creative Commons licence, unless indicated otherwise in a credit line to the material. If material is not included in the article's Creative Commons licence and your intended use is not permitted by statutory regulation or exceeds the permitted use, you will need to obtain permission directly from the copyright holder. To view a copy of this licence, visit http://creativecommons.org/licenses/by/4.0/.

\section{References}

1. Spadoni GL, Cianfarani S. Bone age assessment in the workup of children with endocrine disorders. Horm Res Paediatr. 2010;73:2-5.

2. Martin DD, Wit JM, Hochberg Z, et al. The use of bone age in clinical practice - part 1. Horm Res Paediatr. 2011;76:1-9.

3. Tanner JM, Healy M, Goldstein H, Cameron N. Assessment of skeletal maturity and prediction of adult height (TW3 Method). 3rd ed. London: WB Saunders, Harcourt Publishers Ltd.; 2001. p.1-110.

4. Greulich WW, Pyle SI. Radiographic atlas of skeletal development of the hand and wrist. 2nd ed. Stanford: Stanford University Press; 1959. p.1-272.

5. Thodberg HH, Kreiborg S, Juul A, Pedersen KD. The boneXpert method for automated determination of skeletal maturity. IEEE Trans Med Imaging. 2009;28:52-66.

6. Martin DD, Heil K, Heckmann C, et al. Validation of automatic bone age determination in children with congenital adrenal hyperplasia. Pediatr Radiol. 2013;43:1615-21.

7. Martin DD, Meister K, Schweizer R, Ranke MB, Thodberg HH, Binder G. Validation of automatic bone age rating in children with precocious and early puberty. J Pediatr Endocrinol Metab. 2011;24:1009-14.

8. Nüsken E, Imschinetzki D, Nüsken KD, et al. Automated GreulichPyle bone age determination in children with chronic kidney disease. Pediatr Nephrol. 2015;30:1173-9.

9. Thodberg HH, Jenni OG, Caflisch J, Ranke MB, Martin DD. Prediction of adult height based on automated determination of bone age. J Clin Endocrinol Metab. 2009;94:4868-74.

10. Unrath M, Thodberg HH, Schweizer R, Ranke MB, Binder G, Martin DD. Automation of bone age reading and a new prediction model improve adult height prediction in children with short stature. Horm Res Paediatr. 2012;78:312-9.

11. Reiter EO, Price DA, Wilton P, Albertsson-Wikland K, Ranke MB. Effect of growth hormone $(\mathrm{GH})$ treatment on the near-final height of 1258 patients with idiopathic GH deficiency: analysis of a large international database. J Clin Endocrinol Metab. 2006;91:2047-54.

12. Brandt I, Reinken $L$. The growth rate of healthy children in the first 16 years: Bonn-Dortmund longitudinal developmental study. Klin Padiatr. 1988;200:451-6.

13. Bornstein SR, Allolio B, Arlt W, et al. Diagnosis and treatment of primary adrenal insufficiency: an endocrine society clinical practice guideline. J Clin Endocrinol Metab. 2016;101:364-89.

14. Growth Hormone Research Society. Consensus guidelines for the diagnosis and treatment of growth hormone $(\mathrm{GH})$ deficiency in childhood and adolescence: summary statement of the GH Research Society. GH Research Society. J Clin Endocrinol Metab. 2000;85:3990-3.

15. Lee PA, Chernausek SD, Hokken-Koelega AC, Czernichow P; International Small for Gestational Age Advisory Board. International small for gestational age advisory board consensus development conference statement: management of short children born small for gestational age, April 24-October 1, 2001. Pediatrics. 2003;111:1253-61.

16. Gravholt $\mathrm{CH}$, Andersen NH, Conway GS, et al; International Turner Syndrome Consensus Group. Clinical practice guidelines for the care of girls and women with Turner syndrome: proceedings from the 2016 Cincinnati International Turner Syndrome Meeting. Eur J Endocrinol. 2017;177:G1-70.

17. Thodberg HH. Clinical review: An automated method for determination of bone age. J Clin Endocrinol Metab. 2009;94:2239-44.

18. Bayley N, Pinneau SR. Tables for predicting adult height from skeletal age: revised for use with the Greulich-Pyle hand standards. J Pediatr. 1952;40:423-41.

19. Tanner JM. Growth at adolescence. 2nd ed. Oxford: Blackwell Scientific Publications; 1962. p.1-87.

20. Team RC. A language and environment for statistical computing. 2017. Available at: www.R-project.org. Accessed on 20 Oct 2020.

21. Fletcher TD. Psychometric: Applied Psychometric Theory. R package version 2.2. 2010. Available at: https://cran.r-project. org/. Accessed on 7 July 2020.

22. Thodberg HH, Neuhof J, Ranke MB, Jenni OG, Martin DD. Validation of bone age methods by their ability to predict adult height. Horm Res Paediatr. 2010;74:15-22.

23. Martin DD, Schittenhelm J, Thodberg HH. Validation of adult height prediction based on automated bone age determination in the Paris longitudinal study of healthy children. Pediatr Radiol. 2016;46:263-9.

24. Rohani F, Alai MR, Moradi S, Amirkashani D. Evaluation of near final height in boys with constitutional delay in growth and puberty. Endocr Connect. 2018;7:456-9.

25. Bettendorf M, Heinrich UE, Schonberg DK, Grulich-Henn J. Shortterm, high-dose testosterone treatment fails to reduce adult height in boys with constitutional tall stature. Eur J Pediatr. 1997;156:911-5.

26. Ranke MB, Lindberg A. Growth hormone treatment of idiopathic short stature: analysis of the database from KIGS, the Kabi Pharmacia International Growth Study. Acta Paediatr Suppl. 1994;406:18-23.

27. Groell R, Lindbichler F, Riepl T, Gherra L, Roposch A, Fotter R. The reliability of bone age determination in central European children using the greulich and pyle method. Br J Radiol. 1999;72:461-4. 
28. Satoh M. Bone age: assessment methods and clinical applications. Clin Pediatr Endocrinol. 2015;24:143-52.

29. Ording Müller LS, Offiah A, et al. Bone age for chronological age determination - statement of the European society of paediatric radiology musculoskeletal task force group. Pediatr Radiol. 2019;49:979-82.
30. Shmoish M, German A, Devir N, et al. Prediction of adult height by machine learning technique. J Clin Endocrinol Metab. 2021;106:e2700-10.

Publisher's Note Springer Nature remains neutral with regard to jurisdictional claims in published maps and institutional affiliations. 